\title{
Androgen Insensitivity Syndrome- A Case Report
}

\author{
Tarafdar Runa Laila ${ }^{1}$, Sheikh Salahuddin Ahmed ${ }^{2}$ \\ ${ }^{1}$ Department of Obstetrics \& Gynaecology, University Kuala Lumpur, Royal College of Medicine Perak, Ipoh, Perak, Malaysia \\ ${ }^{2}$ Department of Internal Medicine, University Kuala Lumpur, Royal College of Medicine Perak, Ipoh, Perak, Malaysia
}

Email address:

trlaila@yahoo.com (T. R. Laila)

\section{To cite this article:}

Tarafdar Runa Laila, Sheikh Salahuddin Ahmed. Androgen Insensitivity Syndrome- A Case Report. American Journal of Clinical and Experimental Medicine. Vol. 3, No. 4, 2015, pp. 133-136. doi: 10.11648/j.ajcem.20150304.11

\begin{abstract}
Androgen insensitivity syndrome is a disorder where there is resistance to androgen actions influencing both the morphogenesis and differentiation of androgen responsive body structures. It occurs due to an X-linked mutation in Androgen Receptor gene. This disorder includes a spectrum of changes ranging from male infertility to completely normal female external genitalia in a chromosomally male individual. These cases need proper diagnosis and appropriate management. We report this case for its interesting presentation. The patient is a 20 year old female, presented with bilateral labial swellings and primary amenorrhoea. Subsequent investigations were done which revealed that the patient is a genetically male with absence of female internal genitalia but presence of testes. Gonadectomy was done after proper counseling and was put on hormone replacement therapy. Proper psychological support was also given to her, which is more important.
\end{abstract}

Keywords: Androgen Insensitivity Syndrome, Primary Amenorrhoea, Testicular Feminization Syndrome

\section{Introduction}

Androgen insensitivity syndrome (AIS), formerly known as testicular feminization syndrome, is an X-linked recessive condition resulting in a failure of normal masculinization of the external genitalia in chromosomally male individuals. It depends on an X-linked mutation in the Androgen Receptor (AR) gene that expresses a variety of phenotypes ranging from male infertility to completely normal female external genitalia. The clinical phenotypes of AIS could vary and be classified into three categories, as complete androgen insensitivity syndrome (CAIS), partial androgen insensitivity syndrome (PAIS), and mild androgen insensitivity syndrome (MAIS), according to the severity of androgen resistance [1].

It has a worldwide incidence of 1 in 20,000 to 64,000 male births [2]. Data are currently not available on the specific incidence of androgen insensitivity syndrome in Asian region. Patients with complete androgen insensitivity syndrome (CAIS) are phenotypically normal women and have a risk of developing gonadal malignancy.

Most of the patients are identified in the newborn period by the presence of inguinal masses. But others also present in late adolescent with primary amenorrhoea in addition to inguinal masses. Here we describe a case of CAIS in a 20 -year-old female. The reason of presenting this case is to make the clinicians aware about this important and interesting clinical entity.

\section{Case Report}

A 20 year old unmarried young female of low socio-economic condition came to Gynae outpatient department of a hospital of Bangladesh with history of primary amenorrhoea and bilateral swellings in the vulva for 10 years. According to her statement she had not yet started her menstruation. She also complained of swelling of both sides of the vulva which were present since her childhood, yet she had no medical consultation beforehand. But for the last 1 year they increased in size. However she did not complain of any pain in that region. Her family history revealed that she had 3 sisters among which one of her elder sister had primary amenorrhoea, but she had not undergone any medical consultation.

On examination her vital signs were normal, height $157 \mathrm{~cm}$, weight $60 \mathrm{~kg}$, BMI $23.13 \mathrm{~kg} / \mathrm{m}^{2}$. Secondary sexual characters: breasts well developed, axillary and pubic hairs were sparse.

On per abdominal examination: no abnormality was detected. There was no swelling in the inguinal regions. On local examination there was swelling in both labia majora. On the right side, the swelling was about $4 \times 3 \mathrm{~cm}$ and on the left 
side it was $3 \times 2 \mathrm{~cm}$. The swellings were firm, non-tender, could not be pushed above i.e to the inguinal region. Otherwise the vulva was normal. Vagina was present about $4 \mathrm{~cm}$ but ended blindly. Per rectal examination revealed no uterus or cervix.

Routine blood investigations were normal. USG of the abdomen showed absence of uterus and ovaries. USG of the labial swellings showed structures of homogenous echogenicity which were slightly hypoechoic in nature. Serum FSH and $\mathrm{LH}$ were $40 \mathrm{mIU} / \mathrm{ml}$ and $20 \mathrm{mIU} / \mathrm{ml}$ respectively. Serum testosterone was $11.6 \mathrm{ng} / \mathrm{ml}$. Her karyotyping was done which was $46 \mathrm{XY}$. She was provisionally diagnosed as a case of androgen insensitivity syndrome. As the labial swellings which were supposed to be testes were gradually increasing in size, so decision was taken for excision. At the same sitting diagnostic laparoscopy was done which showed absence of uterus, ovaries and the fallopian tubes. The labial swellings were excised and sent for histopathology. Her post-operative recovery was uneventful. Histopathological examination of the gonad showed seminiferous tubules with normal testicular histopathology and absence of spermatogenesis. There was no evidence of malignancy. The patient is on regular follow-up. She has been prescribed hormone replacement therapy.

\section{Discussion}

Androgen insensitivity syndrome was first described by J.M. Morris an American gynaecologist in 1953 [3]. But we have to wait until 1989 to define the exact location of the human AR gene on Xq11-12 locus and to have proof that it is caused by mutations in this gene $[4,5]$. These mutations are mis-sense mutations which are distributed throughout the eight exons of the androgen receptor gene, but localised mainly in exons that encode the DNA-binding and ligand-binding domains[6].

Androgen insensitivity syndrome represents a spectrum of defects in androgen action and can be subdivided into 3 broad phenotypes: (1) complete androgen insensitivity syndrome (CAIS) with typical female genitalia (2) partial androgen insensitivity syndrome (PAIS) with predominantly female, predominantly male, or ambiguous genitalia and (3) mild androgen insensitivity syndrome (MAIS) with typical male genitalia [1].

The present case is a complete androgen insensitivity syndrome because the phenotype is female in genetic male (46 $\mathrm{XY}$ ). Clinical presentations of these patients vary according to age. In newborns with complete androgen insensitivity syndrome (CAIS), the most frequent initial finding is unilateral or bilateral masses in the inguinal canals that are found to be testes during surgery. Associated hernias may or may not be present [7]. However Papanastasopoulos et al reported a case of AIS in a 12 years old patient who presented with incarcerated inguinal hernia which was ultimately found to be infarcted testes [8]. In adolescent patients, notable findings include primary amenorrhoea with inguinal masses. Our patient also presented with this complaints but she had bilateral labial masses. As with newborns, these masses may or may not be associated with hernias. Our patient also had no hernia. In addition, adolescent patients have no pubic and axillary hair, with otherwise scanty body hair and lack acne, although breasts are normal due to peripheral conversion of testosterone to estradiol. Our patient had all these features. Moreover, in patients with AIS, Anti-Müllerian Hormone $(\mathrm{AMH})$ concentration is normal as the secretion and function of sertoli cell is not impaired [9]. So they do not have fallopian tubes, uterus or a proximal vagina.

The basic etiology of androgen insensitivity syndrome is a loss-of-function mutation in the AR gene. These mutations can cause a variety of functional defects, ranging from a complete loss of receptors on the cell surface to alterations in substrate binding affinity. So inspite of normal level of androgen in the body, the typical post receptor events that mediate the effects of hormones on tissues do not occur. This results in the phenotype of prenatal undervirilization of external genitalia, absence of pubic and axillary hair, lack of acne, and absence of voice changes at puberty.

Endocrine features of CAIS and PAIS are the same: we could observe normal or overproduced serum luteinizing hormone (LH) and Testosterone during the first three months of life. After this, LH and testosterone levels are in the normal range until puberty [10]. Then at puberty, we will find elevated serum levels of testosterone and of $\mathrm{LH}$, due to the androgen insensitivity and the consequent lack of negative feedback exerted by sex hormone on hypothalamus and hypophysis. Testosterone itself becomes target of aromatase, and is converted to estrogens. For this reason CAIS patients present with higher estrogens levels than normal male and have good development of breast. Our patient had also elevated level of $\mathrm{FSH}, \mathrm{LH}$ and testosterone.

A pelvic ultrasound examination is frequently useful. Identification of any müllerian structures, such as uterus or fallopian tubes, is inconsistent with a diagnosis of complete androgen insensitivity syndrome or partial androgen insensitivity syndrome. Final confirmation of the diagnosis in a suspected phenotypic female is by karyotyping.

Androgen insensitivity syndrome, either complete or partial, has little medical morbidity or mortality. However there is a theoretical risk of malignant transformation of testes (gonadoblastoma) and the risk estimate range from $0-22 \%$ in adults with complete androgen insensitivity syndrome [11]. Negussie reported a patient of AIS who in her 35 years of age presented with a large lower abdominal mass in the right lower abdomen and inguinal hernia on the left side [12]. Surgery was done and the right lower abdominal mass was diagnosed as seminoma. For this reason the standard of care is an orchidectomy to prevent possible malignant changes of the testes [13]. The timing of such surgery has been debated. Historically, early surgery was assumed preferable to avoid raising uncomfortable psychosexual issues during adolescence or young adulthood. However surgery during the late teenage years or early $20 \mathrm{~s}$ has been preferred. Later orchidectomy allows pubertal development to occur spontaneously with the production of estrogen from the testosterone. In addition, many women with androgen insensitivity syndrome require vaginal lengthening procedures. 
Orchidectomy and vaginal lengthening procedures may be performed concurrently if surgery is postponed until the patient matures. Our patient did not undergo any sort of vaginoplasty as she was unmarried and had no immediate prospect of marriage.

Cheikhelard et al in their case series of 29 patients with AIS reported that they followed up those patients from their diagnosis at childhood to adulthood [14]. These patients were all of female phenotypes and there was no report of post pubertal virilization and only one patient developed carcinoma in situ (post pubertal). So they advocated of keeping the gonad at least until completion of spontaneous puberty.

Medical care for a patient with androgen insensitivity syndrome (AIS) has 2 aspects: hormone replacement therapy (HRT) and psychological support. All patients with complete androgen insensitivity syndrome (CAIS) and most patients of partial androgen insensitivity syndrome (PAIS) undergo gonadectomy at some point in their treatment. Adolescent and adult patients with androgen insensitivity syndrome require hormone replacement to prevent osteoporosis. Therapy usually is initiated with a low dose of estrogen alone, then is increased to routine adult dosing. Assessment of their bone mineral density is done every few years to ensure adequate treatment.

Psychological support is probably the most important aspect of medical care from the patient's point of view. When the phenotypic females discover themselves to be genetic males they have psychosocial problems which range from identity issues to problems dealing with the gender perceptions of the outside world. Then they become depressed and isolated. At that time they require sensitive psychological support. More difficult is the PAIS when it is not always clear which gender should be assigned. The general consensus is that majority be assigned the male gender and sex of rearing; although cases should be considered on an individual basis.

Androgen insensitivity syndrome prevention includes information about the condition and the woman's risk of having an affected child; so that she can make an informed decision about future childbearing. The carrier females have a $50 \%$ chance of transmitting the mutated AR gene in each pregnancy [2]. So carrier testing is advocated within the family because the disease has known familial tendencies [15]. Rao et al reported a patient of AIS who had this disease in her three generations [16].

\section{Conclusion}

Androgen insensitivity syndrome is distressing to the patient as well as to the family. Systemic disclosure of the diagnosis in an empathic environment with both professional and family support is encouraged. Patient will be benefited by a multidisciplinary approach including gonadectomy, detailed and repeated psychological counseling along with estrogen replacement. The medical and psychological prognosis for a woman with androgen insensitivity syndrome is excellent if she has appropriate support and counseling.

\section{References}

[1] National Center for Biotechnology Information, US National Library of Medicine 2007; Available at http://www.ncbi.nlm.nih.gov/books/NBK1429/. (Accessed September17, 2014).

[2] Hickey M, Balen A. Menstrual disorders in adolescence: Investigation and management. Hum Reproduction Update 2003; 9(5):493-504.

[3] Morris JM. The syndrome of testicular feminization in male pseudohermaphrodite. Am J Obstet Gynecol 1953; 65(6): 1192-1211.

[4] Brown CJ, Goss SJ, Lubahn DB, Joseph DR, Wilson EM, French FS, et al. Androgen receptor locus on the human $\mathrm{X}$ chromosome: regional localization to Xq11-12 and description of a DNA polymorphism. American Journal of Human Genetics 1989; 44(2): 264-269.

[5] Brown TR, Lubahn DB, Wilson EM, Joseph DR, French FS, and Migeon CJ. Deletion of the steroid-binding domain of the human androgen receptor gene in one family with complete androgen insensitivity syndrome: evidence for further genetic heterogeneity in this syndrome. Proceedings of the National Academy of Sciences of the United States of America 1988; 85(21): 8151-8155.

[6] Matias PM, Donner P, Coelho R Thomaz M, Peixoto C, Macedo S, et al. Structural evidence for ligand specificity in the binding domain of the human androgen receptor. Implications for pathogenic gene mutations. J Biol Chem. 2000; 275: 26164-26171

[7] Solari A, Groisman B, Bidondo MP, Cinca C, Alba L. Complete androgen insensitivity syndrome: diagnosis and clinical characteristics. Arch Argent Pediatr 2008; 106(3):265-68.

[8] Papanastasopoulos P, Panagidis A, Verras D, Repanti M, Georgiou G. A case of complete androgen insensitivity syndrome presenting with incarcerated inguinal hernia: an immunohistochemical study. Fertil Steril 2009;. 92(3): 1169.e11-4.

[9] Galani A, Kitsiou-Tzeli S, Sofokleous C, Kanavakis E, and Kalpini-Mavrou A. Androgen insensitivity syndrome: clinical features and molecular defects. Hormones 2008; 7(3): 217-229.

[10] Campo S, Stivel M, Nicolau G. Testicular function in post pubertal male pseudohermaphroditism. Clinical Endocrinology 1979; 11(5):481-490.

[11] Deans R, Creighton SM, Liao LM, Conway GS. Timing of gonadectomy in adult women with complete androgen insensitivity syndrome (CAIS): patient preferences and clinical evidence. Clin Endocrinol (Oxf) 2012;76(6):894-98.

[12] Negussie D. Androgen insensitivity syndrome: a case report. Ethiop Med J 2007;45(3):307-1

[13] Winterborn MH, France NE, Raiti S. Incomplete testicular feminization. Arch Dis Child 1970; 45 (244):811-12.

[14] Cheikhelard A, Morel Y, Thibaud E, Lortat-Jacob S, Jaubert F, Polak M, Nihoul-Fekete C. Long-term followup and comparison between genotype and phenotype in 29 cases of complete androgen insensitivity syndrome. The Journal of urology 2008; 180 (4): 1496-501. 
[15] Boehmer AL, Brinkmann O, Bruggenwirth H, van Assendelft C, Otten BJ, Verleun-Mooijman MC, et al. Genotype versus phenotype in families with androgen insensitivity syndrome. J Clin Endocrinol Metab. 2001; 86(9):4151-4160.
[16] Rao MV, Hydrabadi VR, Chandel D. Complete Androgen Insensitivity in Three Generations of a Family. Int J Hum Genet 2008; 8(4): 361-363. 